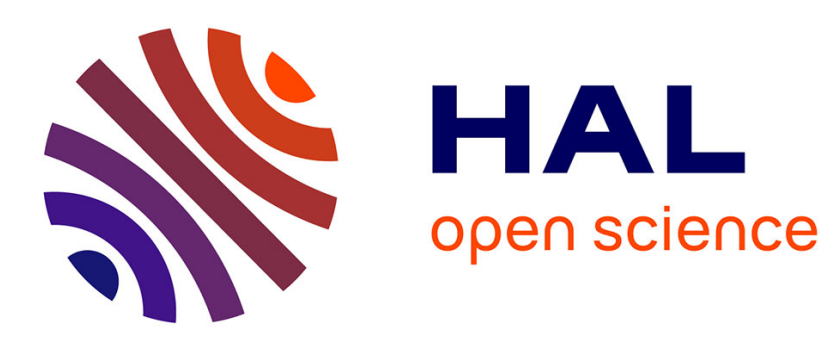

\title{
Study of surface acoustic waves guided by a metallic cylindrical wedge using laser-ultrasonic techniques
}

\author{
D. Auribault, X. Jia, M. de Billy, G. Quentin
}

\section{To cite this version:}

D. Auribault, X. Jia, M. de Billy, G. Quentin. Study of surface acoustic waves guided by a metallic cylindrical wedge using laser-ultrasonic techniques. Journal de Physique IV Proceedings, 1994, 04 (C5), pp.C5-737-C5-740. 10.1051/jp4:19945159 . jpa-00252838

\section{HAL Id: jpa-00252838 https://hal.science/jpa-00252838}

Submitted on 1 Jan 1994

HAL is a multi-disciplinary open access archive for the deposit and dissemination of scientific research documents, whether they are published or not. The documents may come from teaching and research institutions in France or abroad, or from public or private research centers.
L'archive ouverte pluridisciplinaire HAL, est destinée au dépôt et à la diffusion de documents scientifiques de niveau recherche, publiés ou non, émanant des établissements d'enseignement et de recherche français ou étrangers, des laboratoires publics ou privés. 


\title{
Study of surface acoustic waves guided by a metallic cylindrical wedge using laser-ultrasonic techniques
}

\author{
D. AURIBAULT, X. JIA, M. DE BILLY and G. QUENTIN
}

Groupe de Physique des Solides, Université Paris 7, Tour 23, 2 place Jussieu, 75251 Paris cedex 05, France

\begin{abstract}
Résumé : Il a été montré récemment à l'aide d'une technique laser-ultrasons que les ondes guidées se propageant le long d'une arête d'un dièdre rectilligne libre présentent une dispersion causée par la troncature du dièdre inhérente à sa fabrication. L'objectif de ce papier est de rendre compte plus particulièrement de l'influence de la courbure du dièdre, en outre de celle de la troncature, sur les courbes de dispersion de la vitesse de phase des ondes d'arêtes.
\end{abstract}

\begin{abstract}
It was demonstrated with laser-ultrasonic techniques that because of the truncation which exists in actual manufactured wedges, dispersive guided acoustic waves propagate along the tip of a straight wedge. The purpose of this paper is to report an experimental study dealing with wedge acoustic waves travelling along the tip of a free cylindrical metallic wedge. In addition to the effect of the apex truncation, the influence of the surface curvature on the phase velocity dispersion is particularly demonstrated experimentally.
\end{abstract}

\section{INTRODUCTION}

Surface acoustic waves travelling along the tip of an elastic wedge were originally studied in the early 1970s [1-3]. In an idealized infinitely sharp wedge, two types of non dispersive wedge waves are possible: symmetrical modes and antisymetrical flexural modes (ASF modes). The latter modes are particularly attractive because of their possible applications in signal processing devices [2], in geophysics and underwater acoustics [4] as well as in solid surface physics [5].

In a recent experiment [6], it was demonstrated that the slight truncation $(\sim 10 \mu \mathrm{m})$ at the tip of a manufactured metallic wedge "non idealized", introduce a very important dispersion on ASF wedge waves which can not be predicted by the theoretical models [7]. In this paper we will study, using the laser ultrasonic technique, wedge acoustic waves travelling along the tip of cylindrically curved surfaces. In addition to the influence of the apex truncation, the effect of the surface curvature on the dispersion of phase velocity is observed. The preliminary results on the dispersion of phase velocity as function of the curvature radius confirm qualitatively to those theoretically predicted by Krylov [5].

\section{LASER GENERATION AND DETECTION OF ULTRASOUNDS}

The experimental set-up is illustrated in Fig. 1. The ASF wedge modes were generated at the tip of duralumin cylindrical wedges by laser pulses. The propagation of the excited waves along the wedge was detected by means of an optical heterodyne interferometer [8]. The YAG laser $(\lambda=1.06 \mu \mathrm{m})$ used for the wave generation provided an optical pulse of $6 \mathrm{~ns}$-duration and $5 \mathrm{~mJ}$-energy. The impact laser beam was focused onto a $0.4 \mathrm{~mm}$ spot on the wedge under study. Both YAG laser impact and optical probe beam $(0.1$ $\mathrm{mm}$ in diameter) were positioned at the top of the cylindrical wedge (Fig.1) diametrically opposite. The optical probe associated with the broadband electronic detection, allows us to measure the normal components of the mechanical displacement. The probed signals are sampled and averaged by a digital oscilloscope and then sent to a microcomputer for calculations.

\section{EXPERIMENTAL RESULTS AND DISCUSSION}

In Fig. 2 is shown a typical displacement waveform observed on a duralumin cylindrical wedge of $30^{\circ}$-apex angle and $10 \mathrm{~mm}$-radius. The mean apex truncation about $20 \mu \mathrm{m}$ was measured at the tip of the 


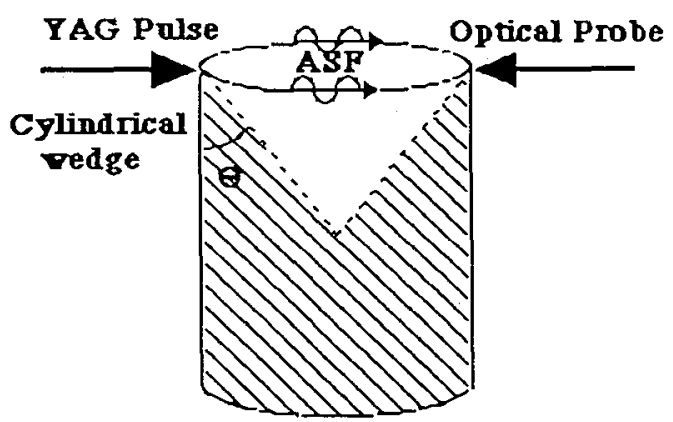

Fig. 1 Laser generation and detection of ASF modes in a cylindrical wedge.

wedge. In this record we notice the presence of signals regularly spaced which correspond to the detection of the ASF modes propagating around the cylindrical wedge after $1,2, \ldots$ rounds. Contrary to Rayleigh and Lamb types of circumferential waves propagating in a cylinder $[9,10]$, ASF modes persist much more longer during the repeated circumnavigation owing to their lateral diffraction absence. The waveforms of ASF modes are characterized by a dispersion behaviour with the high frequency components arriving first, and the widths of the ASF pulses become more and more larger as they propagate. As mentionned previously, two mechanisms may be responsible for this dispersion effect: one is the apex truncation, the other is the surface curvature.

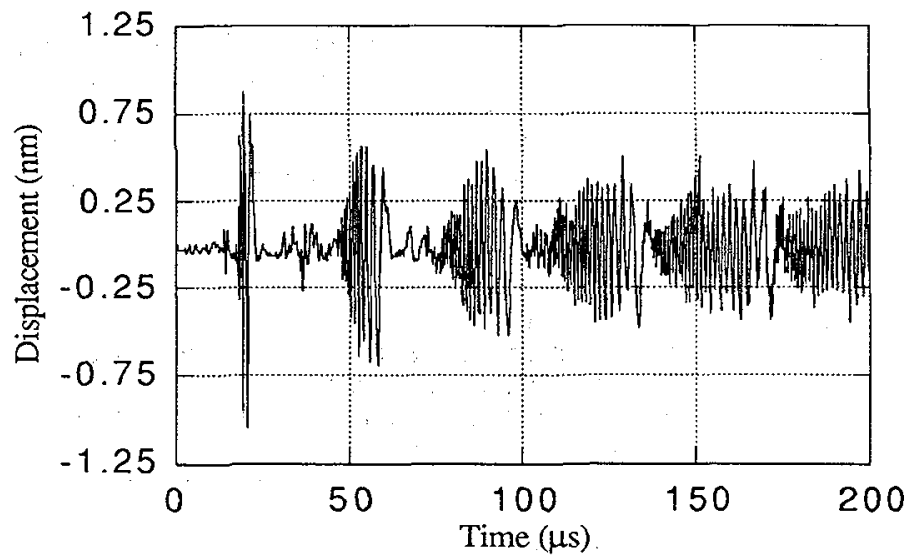

Fig. 2 Displacement waveform of ASF modes guided by a cylindrical wedge of $18 \mathrm{~mm}$ diameter

\subsection{Influence of the apex truncation}

In order to investigate separately the effects of the apex truncation and surface curvature on the ASF mode dispesion, the experiments were made with two types of cylindrical wedge samples. In the first one, the wedges have the same curvature radius but different apex truncations. In the second one, they keep almost the same truncation at the tip but have the different radius. All these cylindrical wedges have the same apex angle of $30^{\circ}$ and are made of duralumin. Figs. $3 \mathrm{a}$ and $3 \mathrm{~b}$ present the displacements detected at the cylindrical wedges with the apex trunction of $10 \mu \mathrm{m}$ and $100 \mu \mathrm{m}$, respectively. The radius of these cylinders are $20 \mathrm{~mm}$. As in the case of a straight wedge [6], three modes are observed A1, A2 and A3. The waveform is quite different from the wedge of $10 \mu \mathrm{m}$ apex truncation to that of $100 \mu \mathrm{m}$. This modification is particularly remarked for the dominant fundamental mode in which the pulses arrive earlier in the more truncated wedge, especially for the high frequencies components. To quantify the dispersion properties of these modes, a phase analysis technique of broadband ultrasonic pulses [6] was used to deduce the dispersion curves of the phase velocity. In Figs. $4 \mathrm{a}$ and $4 \mathrm{~b}$ are plotted the dispersion curves of phase velocity versus the product $(\mathrm{kT})$ of wavenumber by apex truncation. The phase velocities increase with $\mathrm{kT}$ as qualitatively predicted by theoretical models [7]. In the zero frequency limit, they tend towards the values 
$(1450 \mathrm{~m} / \mathrm{s})$ of the fundamental ASF mode in an idealized straight wedge of $30^{\circ}$ apex angle predicted by Lagasse [1]. This implies that the effect of apex truncation on phase velocity is negligible in the limit of low frequency.
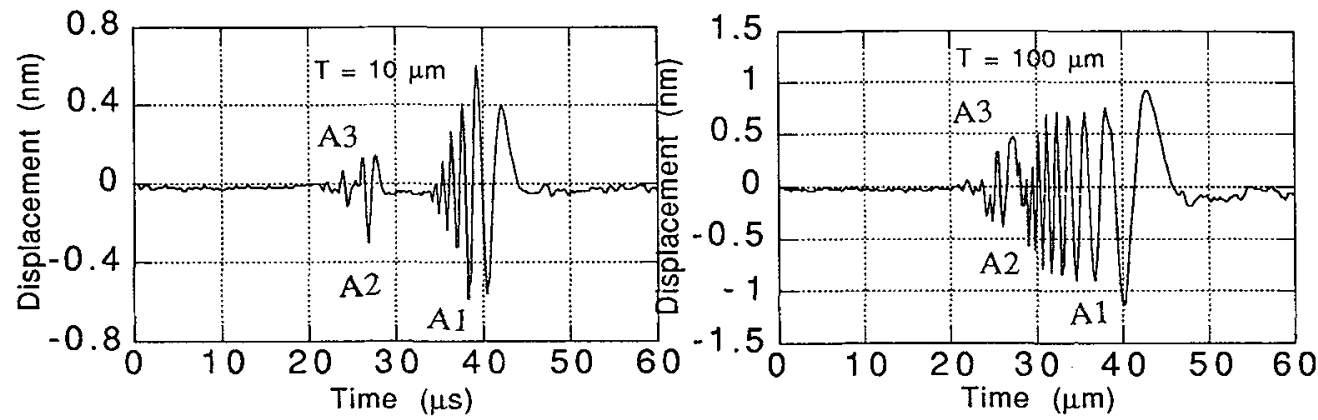

Fig. 3 Displacement waveforms of ASF modes measured on the cylindrical wedges of $10 \mu \mathrm{m}$ (a) and 100 $\mu \mathrm{m}$ apex truncation, respectively. The radius of these cylindrical wedges are $20 \mathrm{~mm}$ and the apex angle are $30^{\circ}$.
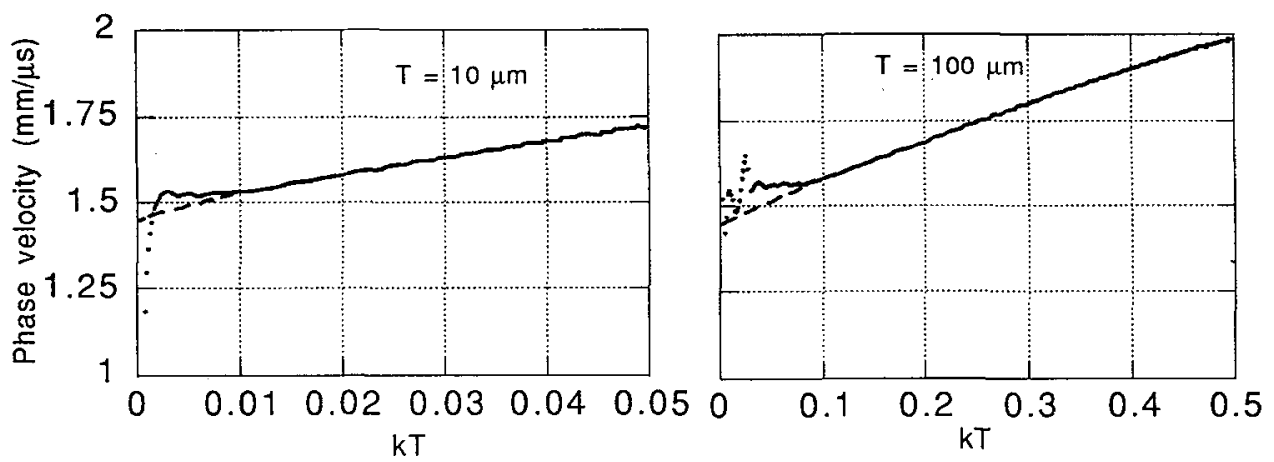

Fig. 4 Phase velocities of the fundamental ASF modes deduced from Fig. 3a and b. kT is the product of the wavenumber by the apex truncation.

\subsection{Influence of the surface curvature}

We study now the influence of surface curvature on the phase velocity dispersion of ASF modes. Five cylindrical wedges were investigated. The apex angles of all these wedges are $30^{\circ}$, but their radius are variable: $10,20,30,40$ and infinity (straight wedge). It was observed that cylindrical wedges presented variable truncations at the tips introduced by the mechanical procedure during the realisation of the samples. For investigating the proper effect of the surface curvature on the dispersion property of ASF modes, our measurements were done with a great care in the chosen section of the cylindrical wedges along which the apex truncations $\mathrm{T}=10 \pm 5 \mu \mathrm{m}$ remain nearly constant. The plots of the dispersion curves are given in Fig. 5 , which were obtained using the preceding phase analysis technique. These curves show that the phase velocities increase as the curvature radius decrease. The extrapolated values of the phase velocities in zero frequency limit are different for each cylindrical wedge. These differences in the phase velocity should be essentially due to the surface curvature effect, since the apex truncation effect on the dispersion property is small in the low frequency range as mentionned in the last paragraph. This experimental result is qualitatively in agreement with the theoretical predictions (Eq. 13 of Ref. 5). In Fig. 6 is plotted the variation of the normalized phase velocity versus the product $(\mathrm{ka})$ of wavenumber by radius for a low given frequency of $0.1 \mathrm{MHz}$. We observe that the surface curvature effect on ASF modes is similar to that on Rayleigh surface wave [9]. 


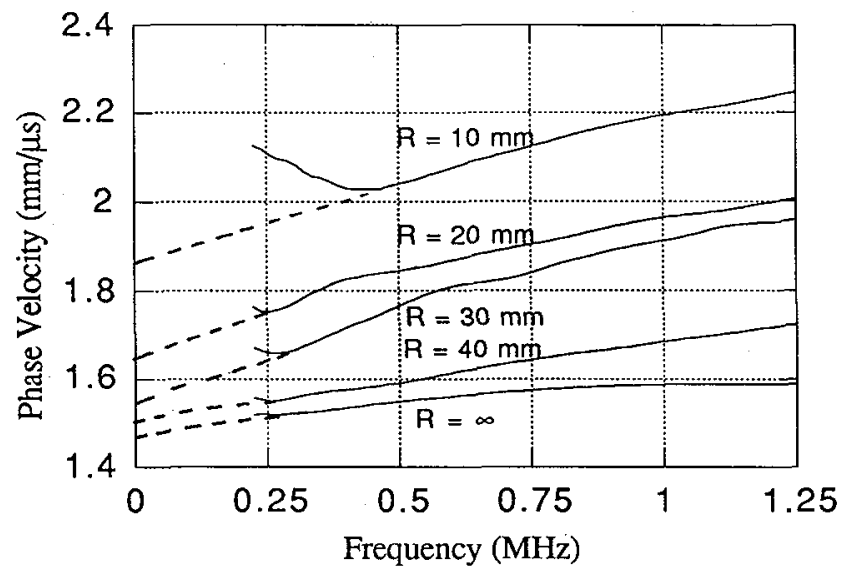

Fig. 5 Dispersion curves of phase velocity of the fundamental ASF modes obtained on cylindrical wedges of different curvature radius. The apex angle and truncation are respectively $30^{\circ}$ and $10 \mu \mathrm{m}$.

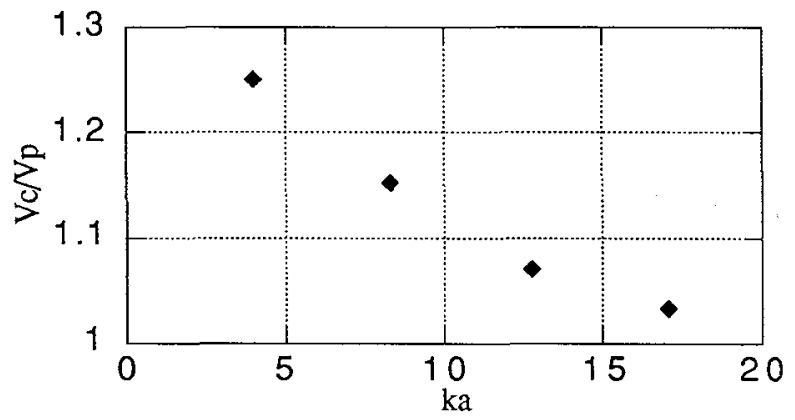

Fig. 6 Normalised phase velocity of ASF modes on curved wedges versus $\mathrm{ka}$. Vp is the phase velocity of the fundamental ASF mode in a straight wedge.

\section{SUMMARY}

ASF waves propagating in tips of curved cylindrical wedges have been investigated using laser generation and detection. The influences of the apex truncation and curvature radius on the dispersion property of phase velocity were studied. These results confirm qualitatively the theoretical predictions. More quantitative study is in progress on the dispersion characteristics of ASF waves as well as the effects of surrounding medium.

\section{REFERENCES}

[1] Lagasse P.E., Electon. Lett. (1972), 8, 372.

[2] Lagasse P.E., Mason I.A.and Ash E.A., IEEE Trans. SU-20, 143 (1973)

[3] Maradudin A.A, Wallis R.F., Mills D.L.and Ballard R.L, Phys. Rev B6, 1106 (1972)

[4] Chamuel J.R., Report n JRC 34-91, Sonoquest Advanced Ultrasonic Research (1991)

[5] Krylov V.V., II International Symposium on surface waves in solids and layered structures (Bulgaria, 1989) 174

[6] Jia X. and de Billy M., Appl. Phys. Lett. 61, 2970 (1992)

[7] McKenna J., Boyd G.D. and Thurston R.N., IEEE Trans. SU-21, 178 (1974)

[8] Royer D. and Dieulesaint E., Proceedings of 1986 IEEE Ultrasonics Symposium, 527

[9] Viktorov I.A., Rayleigh and Lamb waves, Plenum Press, New York, 1967

[10] Jia X., Thèse de Doctorat, Université P. et M. Curie (Paris, 1988) 